\title{
A Study on the Effects of Starches on the Properties of Alkali-Activated Cement and the Potential of Starch as a Self-Degradable Additive
}

\author{
Huijing Tan, Xiuhua Zheng *, Limenglu Ma, Haixiao Huang and Bairu Xia \\ School of Engineering and Technology, China University of Geosciences (Beijing), Beijing 100083, China; \\ huijingtan@cugb.edu.cn (H.T.); mlml@cugb.edu.cn (L.M.); 2102150071@cugb.edu.cn (H.H.); \\ brxia@cugb.edu.cn (B.X.) \\ * Correspondence: xiuhuazh@cugb.edu.cn; Tel.: +86-10-8232-2624
}

Received: 12 May 2017; Accepted: 18 July 2017; Published: 20 July 2017

\begin{abstract}
An urgent problem of geothermal energy source development is how to cut down the production costs. The use of temporary sealing materials can reduce the costs associated with the circulation lost by plugging, and increase the production by self-degradation. Based on the utilization of starches as self-degradable additives in the medical field, this paper investigated the effects of three kinds of starches, namely corn starch (CS), hydroxypropyl starch (HPS) and carboxymethyl starch (CMS) on the properties of alkali-activated cement (AAC). In addition, the thermal properties of starch, the compressive strength and microstructures of the cement with starch were tested, to evaluate the potentiality of starch as self-degradable additive for geothermal cement. The analysis showed that: (1) all the starches have the effect of increasing the apparent viscosity, prolonging the setting time and reducing the static fluid loss of alkali-activated cement; (2) the addition of starch increased the number of pores in $200{ }^{\circ} \mathrm{C}$-heated cement, facilitated the leaching process, and thus promoted the self-degradation; and (3) among the three starches, CMS has the most potential as a self-degradable additive.
\end{abstract}

Keywords: alkali-activated cement; starch; self-degradable additives; geothermal wells

\section{Introduction}

Geothermal reservoirs are usually constructed in fractured formations, which results in the lost circulation problem during drilling operations. Lost circulation leads to increased material waste and the time cost of non-drilling. The cost associated with the lost circulation usually accounts for more than $20 \%$ of the total costs for drilling in geothermal development [1-3]. Therefore, the fractured formations must be plugged in order to reduce the development costs.

Besides the high temperature, another feature that geothermal reservoirs have is that the reservoirs contain corrosive gases, such as $\mathrm{CO}_{2}$ and $\mathrm{H}_{2} \mathrm{~S}$ [4]. This feature requires that any sealing material have high temperature resistance and corrosion resistance. Alkali-activated cementitious materials (AAC) are resistant to high temperature and acid corrosion, compared with the failure of Portland cement [5]. Binder gels, as the main reaction product in these hydrated $\mathrm{Na}_{2} \mathrm{O}-\mathrm{CaO}-\mathrm{Al}_{2} \mathrm{O}_{3}-\mathrm{SiO}_{2}$ systems, promote the development of high mechanical strength and durability. The gels, not significantly affected by exposure to elevated temperatures, also protect the materials from acid corrosion [6,7]. The utilization of industrial by-products to produce alkali-activated cement decreases the negative impacts on environment [8]. Slag and fly ash are the industrial by-products most frequently used to manufacture AAC.

After the fractures are plugged with the sealing materials to resume the drilling operations until the wellbore structure is completed, the fractures should be opened later by disintegration for the 
hydraulic-stimulation process. The drilling temperatures of geothermal wells seldom exceed $116^{\circ} \mathrm{C}$, with an average temperature of around $85^{\circ} \mathrm{C}$, due to the cooling effect of circulating fluids. However, the well temperature can rise up to more than $200{ }^{\circ} \mathrm{C}$ under static conditions, when the drilling is completed $[9,10]$. The ideal material should provide sufficient strength to seal the fractured formations and prevent lost circulation at about $85^{\circ} \mathrm{C}$, but degrade after the drilling operation at $200{ }^{\circ} \mathrm{C}$ and contact with water.

Scientists at Brookhaven National Laboratory have added sodium carboxymethyl cellulose (CMC) into sodium metasilicate-activated slag/Class $C$ fly ash cementitious materials, to develop temporary sealing materials $[10,11]$. The thermal degradation properties of CMC, the compressive strength, porosity and the self-degradation of the cement were tested. The conclusion was reached that high molecular weight CMC rendered two important features to the water-catalyzed self-degradation of heated cement: one was the high heat generated in exothermic reactions in cement; the other was the introduction of extensive porosity into the cement. The shortcoming of the material is that the addition of CMC significantly increased the viscosity, which has a negative effect on the pumpability of cement slurries.

The viscosity of $1 \%$ high molecular weight CMC solution reaches about $400 \sim 500 \mathrm{mPa} \cdot \mathrm{s}$ [12]. When starch is used in a drilling fluid, it has little effect on the plastic viscosity, and the viscosity of $2 \%$ starch solution is in general below $120 \mathrm{mPa} \cdot \mathrm{s}$ [12]. Starch is similar to CMC in chemical constitution and thermal degradation properties [13]. It has also been used in drilling fluids as a filtrate reducer. Besides being widely used as biodegradable additives in biodegradable cement [14], starch has also been usually used to develop starch-based water reducing agents and hydration heat regulating materials [15-17]. Therefore, this paper studied the effects of starch on the properties of alkali-activated cement, and investigated the potential of starch as a self-degradable additive. The results of the study will be of reference and guiding significance to the application of starch in the field of geothermal cement development.

Lost circulation causes material waste and an increase in non-productive time, and leads to the risk of the wellbore instability (collapse) [18-20]. In addition, after the drilling operation is resumed by using the materials and continues until the wellbore structure is completed, the hydraulic stimulation process begins. The ideal materials will disintegrate both in hot water at $200{ }^{\circ} \mathrm{C}$ and when coming in contact with water during stimulation operations after exposure to dry heat at $200{ }^{\circ} \mathrm{C}$, depending on the geothermal well conditions. As the hydraulic stimulation initiates the opening of existing fractures [21,22], the sealing materials that were used to plug the fractures must be disintegrated by high pressure water to reopen the sealed fractures. However, the self-degradation of the ideal material will happen during the changes of geothermal well conditions, not consume additional operating time and materials, and thus further save costs.

The rheological properties at room temperature, the setting times at $85^{\circ} \mathrm{C}$, the static fluid loss, the compressive strength and the hydration products of cement after curing at $85{ }^{\circ} \mathrm{C}$ were studied to investigate the effects of corn starch (CS), hydroxypropyl starch (HPS) and carboxymethyl starch (CMS) on the properties of alkali-activated cement. In addition, the thermal properties of the starches, the compressive strength and microstructures of $85^{\circ} \mathrm{C}$-cured cement after $200{ }^{\circ} \mathrm{C}$-heated and immersed in water, were studied to evaluate the potentiality of the starch as self-degradable additives.

\section{Materials and Methods}

\subsection{Materials}

Corn starch (CS), hydroxypropyl starch (HPS) and carboxymethyl starch (CMS) were respectively obtained from Kanglida Food Co., Ltd. (Beijing, China), Baiying Biology Technology Co., Ltd. (Jiangxi, China) and Runda Chemical Co., Ltd. (Renqiu, China). The physical and chemical characteristics of the starches are shown in Table 1. Fineness is the weight percent of particles in starch with a size smaller than $150 \mu \mathrm{m}$. The viscosity refers to the apparent viscosity of a 3\% (w/v) starch suspension. 
The swelling power $(\mathrm{g} / \mathrm{g})$ and solubility $(\%)$ were determined according to the method described by Rafiq (as shown in the measurements) [23].

Table 1. The physical and chemical parameters of starches.

\begin{tabular}{|c|c|c|c|}
\hline Parameters & CS & HPS & CMS \\
\hline Appearance and odor & \multicolumn{3}{|c|}{ White powder and no odor } \\
\hline Fineness (\%) & 96.52 & 97.37 & 95.24 \\
\hline Viscosity $(\mathrm{mPa} \cdot \mathrm{s})$ & 5.3 & 25.6 & 48.0 \\
\hline Water content $(\%)$ & 7.05 & 5.21 & 8.57 \\
\hline $\mathrm{pH}(3 \%)$ & 7.34 & 7.26 & 10.12 \\
\hline Swelling power $(\mathrm{g} / \mathrm{g})$ & 9.16 & 26.38 & 47.65 \\
\hline Solubility (\%) & 5.49 & 3.81 & 1.21 \\
\hline
\end{tabular}

The slag was obtained from Xinding Minerals Processing Plant (Lingshou, China). The fly ash was supplied by Luyuan Power Resource Development Groups Co., Ltd. (Dongying, China). Sodium metasilicate was supplied by Qingdao Yousuo Chemical Technologies, Inc. (Qingdao, China). The chemical compositions of slag and fly ash measured by Inductively Coupled Plasma-Atomic Emission Spectrometric (ICP-AES) are shown in Table 2. The weight percent of uncertain components of the fly ash and slag are presented as "others".

Table 2. The chemical compositions of slag and fly ash detected by ICP-AES.

\begin{tabular}{cccccccccc}
\hline Component & $\mathbf{C a O}$ & $\mathbf{S i O}_{\mathbf{2}}$ & $\mathbf{A l}_{\mathbf{2}} \mathbf{O}_{\mathbf{3}}$ & $\mathbf{M g O}$ & $\mathbf{F e}_{\mathbf{2}} \mathbf{O}_{\mathbf{3}}$ & $\mathbf{K}_{\mathbf{2}} \mathbf{O}$ & $\mathbf{T i O}_{2}$ & $\mathbf{M n O}$ & Others \\
\hline Fly ash & 17.70 & 37.33 & 20.42 & 1.96 & 4.93 & 1.18 & 0.79 & 0.06 & 16.48 \\
Slag & 36.55 & 31.13 & 14.37 & 9.13 & 0.52 & 0.42 & 1.19 & 0.31 & 7.88 \\
\hline
\end{tabular}

The AAC formula had slag/Class $\mathrm{C}$ fly ash ratio of $80 / 20$ by weight. $6 \%$ sodium metasilicate with a silica modulus $\left(\mathrm{SiO}_{2} / \mathrm{Na}_{2} \mathrm{O}\right)$ of 1 was added by total weight to the dry pozzolana cement. Water was added at a water/dry pozzolana cement ratio of 0.6 to prepare the cement paste. The starches and dry pozzolana cement were blended thoroughly and uniformly prior to being added to water. The AAC without any starches was considered as control sample. The three kinds of starches, CS, HPS and CMS, were added into AAC by the total weight of pozzolana cement. AAC with $1 \%, 2 \%$ and $3 \%$ of starches were cured in air at room temperature for $72 \mathrm{~h}$, afterwards, all set cements were cured at $85^{\circ} \mathrm{C}$ for $24 \mathrm{~h}$ $\left(85^{\circ} \mathrm{C}\right.$-cured). In addition, AAC with $3 \%$ starches were further heated for $24 \mathrm{~h}$ in an oven at $200{ }^{\circ} \mathrm{C}$ $\left(200{ }^{\circ} \mathrm{C}\right.$-heated), and then immersed in water for $2 \mathrm{~h}$ and $24 \mathrm{~h}$. The starch powders $(4 \mathrm{~g})$ were immersed in filtrate $(15 \mathrm{~mL}$ ) obtained by an API filter tester (Haitongda SD6, Qingdao, China) from the control slurry. The starches immersed in filtrate were cured at room temperature for $72 \mathrm{~h}$ and at $85^{\circ} \mathrm{C}$ for $24 \mathrm{~h}$, and then dried at $105{ }^{\circ} \mathrm{C}$ for $5 \mathrm{~h}$ to prepare filtrate-treated starch. The preparation of water-immersed starch is similar to the preparation of the filtrate-treated starch, except for the substitution of water by cement filtrate.

\subsection{Measurements}

Starch samples ( $500 \mathrm{mg}$, dry basis) taken in pre-weighed centrifuge tubes with $25 \mathrm{~mL}$ of distilled water were heated at $85^{\circ} \mathrm{C}$ in a water bath for $1 \mathrm{~h}$. The suspension was then cooled to room temperature and centrifuged at $3000 \mathrm{r} / \mathrm{min}$ for $15 \mathrm{~min}$. The supernatant obtained was carefully decanted in pre-weighed Petri dishes and dried at $110^{\circ} \mathrm{C}$ in a hot air oven until a constant weight (A) was obtained. The swollen starch sediment was weighed (B) for calculating swelling power. Swelling power $(\mathrm{g} / \mathrm{g})$ and solubility (\%) were calculated from the given equations:

$$
\begin{gathered}
\text { Solubility }=\frac{A}{S} \times 100, \\
\text { Swelling power }=B \times \frac{100}{S(100-\text { Solubility })},
\end{gathered}
$$


where $\mathrm{A}=$ weight of dried supernatant. $\mathrm{B}=$ weight of wet sediment. $\mathrm{S}=$ weight of sample.

The apparent viscosities at different rotational speeds of the cement slurries containing $1 \%$ CS, HPS and CMS, respectively, were measured on a Brookfield viscometer (Brookfield 8542373, Middleboro, MA, USA).

The fluid loss of control and AAC with $1 \%, 2 \%$ and $3 \%$ starch at room temperature medium pressure (RTMP $20^{\circ} \mathrm{C}$ and $0.69 \mathrm{MPa}$ ) for $7.5 \mathrm{~min}$ and high temperature high pressure (HTHP, $85^{\circ} \mathrm{C}$ and $3.15 \mathrm{MPa}$ ) for $7.5 \mathrm{~min}$ were respectively measured on an API Filter Tester and HTHP Filter Tester (Haitongda GGS42-2, Qingdao, China).

The setting times of AAC with $1 \%, 2 \%$ and $3 \%$ starch were measured according to Chinese National Standard GB/T1346-2011, on a Vicat needle apparatus (Shengweike SKW-ISO, Tianjin, China), at $85^{\circ} \mathrm{C}$.

Compressive strength was tested according to Chinese National Standard GB 10238-2005 and Chinese Petroleum and Natural Gas Industry Standard SY / T 6544-2010 on a servo universal testing machine (Chandler YAW-300B, Chengdu, China) with a loading rate of $17.1 \mathrm{kN} / \mathrm{min}$. The cube samples with the size of $50.8 \mathrm{~mm} \times 50.8 \mathrm{~mm} \times 50.8 \mathrm{~mm}(2$ in $\times 2$ in $\times 2$ in) were casted. Three cubic specimens of each composition were prepared to measure the compressive strength.

Powder X-ray diffraction (XRD) carried out on a diffractometer (Rigaku D/max, Tokyo, Japan) was employed to identify the crystalline phases of the $85^{\circ} \mathrm{C}$-cured and $200^{\circ} \mathrm{C}$-heated samples. The samples were crushed, ground and passed through a 300 mesh screen. The scanning regions were between $2 \theta$ values of $3^{\circ}$ and $70^{\circ}$, at a resolution of $0.02^{\circ} /$ step.

The thermal degradation properties of raw and filtrate-treated starch were checked on a Thermo Gravimetric Analyzer (TA Instruments Q600, New Castle, DE, USA) under a nitrogen atmosphere with the temperature range from a room temperature of ca. $20.0^{\circ} \mathrm{C}$ to $450.0^{\circ} \mathrm{C}$ at a heating rate of $10.0^{\circ} \mathrm{C} / \mathrm{min}$.

Fourier Transform Infrared Spectrometry (FTIR) experiments were conducted to investigate the volume expansion effects of filtrate on starches. The IR spectra of starches were run as $\mathrm{KBr}$ pellets on an impact spectrometer (410 FTIR, Nicolet, Madison, WI, USA) in the frequency range $4000-400 \mathrm{~cm}^{-1}$.

The microstructures of AAC with 3\% different starches immersed in water for $24 \mathrm{~h}$ were observed on a Scanning Electron Microscopy (XL30SFEG, FEI, Hillsboro, OR, USA) running at an accelerating voltage of $20 \mathrm{kV}$.

The gelatinization profiles of the starches with distilled water (CS, HPS and CMS) and the starches with the cement filtrate (CS-1, HPS-1 and CMS-1) were measured on a differential scanning calorimetry (DSC). The $6 \mathrm{~g}$ starches were mixed with $20 \mathrm{~mL}$ distilled water or cement filtrate to prepare the samples. DSC (TA Instruments Q2000) test was carried out under a nitrogen atmosphere $(50 \mathrm{~mL} / \mathrm{min})$ with a scan rate of $10{ }^{\circ} \mathrm{C} / \mathrm{min}$ from $20^{\circ} \mathrm{C}$ to $100{ }^{\circ} \mathrm{C}$. The $5-10 \mathrm{mg}$ liquid samples were sealed in hermetic aluminum crucibles.

The Barrett-Joyner-Halenda (BJH) pore size distribution $(<130 \mathrm{~nm})$ was determined by $\mathrm{N}_{2}$ gas adsorption on a Quadrasorb SI device, manufactured by Quantachrome Instrument Corp. (Boynton Beach, FL, USA). The apparent porosity test was carried out on the cube samples with the size of $50.8 \mathrm{~mm} \times 50.8 \mathrm{~mm} \times 50.8 \mathrm{~mm}$. According to ASTM C-20 Standard [24], the apparent porosity (\%) was calculated with the following equation:

$$
P_{s}=\frac{m_{s}-m_{d}}{m_{s}-m_{i}} \times 100,
$$

where $m_{s}=$ mass of the sample saturated in water $(\mathrm{g}), m_{d}=$ mass of the dried sample $(\mathrm{g}), m_{i}=$ mass of the sample saturated with and suspended in water $(\mathrm{g})$.

\section{Results and Discussion}

\subsection{Rheological Properties}

The rheological properties are an important index to evaluate the performance of cement [25]. The rheological properties play an important role in the application of cement. For example, as a 
large viscosity has negative impact on the pumping, the viscosity of cement must be kept low enough to ensure pumpability, in the cementing process at the drilling field [26]. Undesirable rheological properties also lead to the settling of solids in cement compositions, which results in defective cementing and failure of the set cement to provide zonal isolation. However, the addition of CMC significantly increased the viscosity of cement, which has a negative effect on its pumpability.

As shown in Figure 1, all the starches have enhancing effects on the viscosity of cement slurry. At the test rotational speeds of $10 \mathrm{r} / \mathrm{min}$ and $50 \mathrm{r} / \mathrm{min}$, the apparent viscosities of AAC containing $1 \% \mathrm{CS}$, are $1740 \mathrm{mPa} \cdot \mathrm{s}$ and $611.9 \mathrm{mPa} \cdot \mathrm{s}$, the apparent viscosities of AAC containing $1 \% \mathrm{HPS}$ are $1020 \mathrm{mPa} \cdot \mathrm{s}$ and $419.9 \mathrm{mPa} \cdot \mathrm{s}$, and the apparent viscosities of AAC containing 1\% CMS are $1980 \mathrm{mPa} \cdot \mathrm{s}$ and $851.8 \mathrm{mPa} \cdot \mathrm{s}$. The effect sequence of starches on cement viscosity is as follows: CMS > CS > HPS. As reported in literature [27], the addition of an alkali component to the starch significantly enhances the swelling of the starch granules and expedites the gelatinization process. As the AAC slurry is alkaline, it expedites starch gelatinization. The swollen amorphous starch granules increased the viscosity of the cement slurry, as a resulted of their increased spatial volume around the granules.

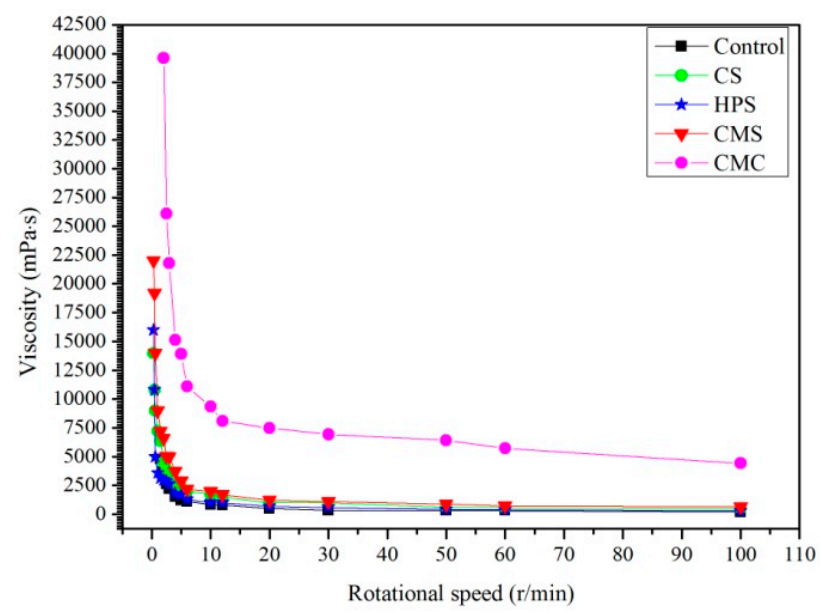

Figure 1. The apparent viscosities of control and AAC with $1 \%$ CS, HPS, CMS or CMC, at different rotational speeds.

The apparent viscosity of cement slurry decreases rapidly with the increasing rotational speed. As the rotational speed increases from $1.5 \mathrm{r} / \mathrm{min}$ to $100 \mathrm{r} / \mathrm{min}$, the apparent viscosity of AAC with $1 \%$ CMS decreases from $7198 \mathrm{mPa} \cdot \mathrm{s}$ to $659.9 \mathrm{mPa} \cdot \mathrm{s}$; AAC with $1 \%$ HPS decreases from $3159 \mathrm{mPa} \cdot \mathrm{s}$ to $259.9 \mathrm{mPa} \cdot \mathrm{s}$; AAC with $1 \%$ CS decreases from $6399 \mathrm{mPa} \cdot \mathrm{s}$ to $521.9 \mathrm{mPa} \cdot \mathrm{s}$; the apparent viscosity of control decreases from $4799 \mathrm{mPa} \cdot \mathrm{s}$ to $198.0 \mathrm{mPa} \cdot \mathrm{s}$. The viscosity of AAC with $1 \%$ CMS declines the most rapidly along with the increase of rotational speed, indicating that it exhibits the most obvious shear-thinning phenomenon.

All of the cement slurries in this paper show obvious shear-thinning phenomena. Besides that, at the test rotational speeds of $10 \mathrm{r} / \mathrm{min}$ and $50 \mathrm{r} / \mathrm{min}$, the apparent viscosities of AAC with $1 \% \mathrm{CMC}$ are $9358 \mathrm{mPa} \cdot \mathrm{s}$ and $6419 \mathrm{mPa} \cdot \mathrm{s}$. The increasing effect of CMC is distinctly stronger than that of the three starches with the same dosage, as shown in Figure 1. The results indicate that the substitution of starches for CMC can enhance the pumpability of the cement slurry by decreasing the viscosity.

\subsection{Static Fluid Loss}

In cementing operations, a large fluid loss of cement leads to a massive water loss, which has a negative influence on cementing quality by slowing down the hydration to decline the strength of cement [28]. What is worse is that some fine cement particles enter the rock, together with the massive water lost from the cement slurries, plug the pores and reduce the permeability of rock, and thus result in a decline of fluid production [29]. Starch has been widely used in drilling fluids as fluid 
loss reducers. In drilling fluids, starch decreases the fluid loss by two approaches: on the one hand, the starch absorbs moisture to reduce the free water; on the other hand, vesicular substances formed by starch can enter into the spaces of mud cake to plug the path way of water, and further reduce the fluid loss [18].

As shown in Figure 2, the RTMP static fluid loss of control is $78.4 \mathrm{~mL}$; the RTMP static fluid loss of AAC with $3 \%$ CS is $50.7 \mathrm{~mL}$; the RTMP static fluid loss of AAC with $3 \% \mathrm{HPS}$ and CMS are $53.5 \mathrm{~mL}$ and $48.6 \mathrm{~mL}$. As the addition of 3\% CS, the RTMP fluid loss is decreased by $35.3 \%$; as the addition of $3 \%$ HPS and CMS, the RTMP fluid loss is decreased by $31.8 \%$ and $38.0 \%$, respectively. The HTHP static fluid loss of AAC with $3 \%$ CS is $61.3 \mathrm{~mL}$, decreased by $41.0 \%$, when compared to control; the HTHP static fluid loss of AAC with 3\% HPS and CMS are $75.7 \mathrm{~mL}$ and $56.9 \mathrm{~mL}$, decreased by $27.1 \%$ and $45.2 \%$. In addition, both the RTMP and HTHP fluid loss decrease as starch dosages increase: the RTMP fluid loss of AAC with 1\% CMS is $54.3 \mathrm{~mL}$, which declines to $48.6 \mathrm{~mL}$, as the CMS dosage rises to $3 \%$; the HTHP fluid loss of AAC with 1\% CMS is decreased by $12.67 \%$, from $65.2 \mathrm{~mL}$ to $56.9 \mathrm{~mL}$, as the CMS dosage rises to $3 \%$. Among these three starches, CMS has the greatest decreasing effect on static fluid loss, both on RTMP and HTHP fluid loss.

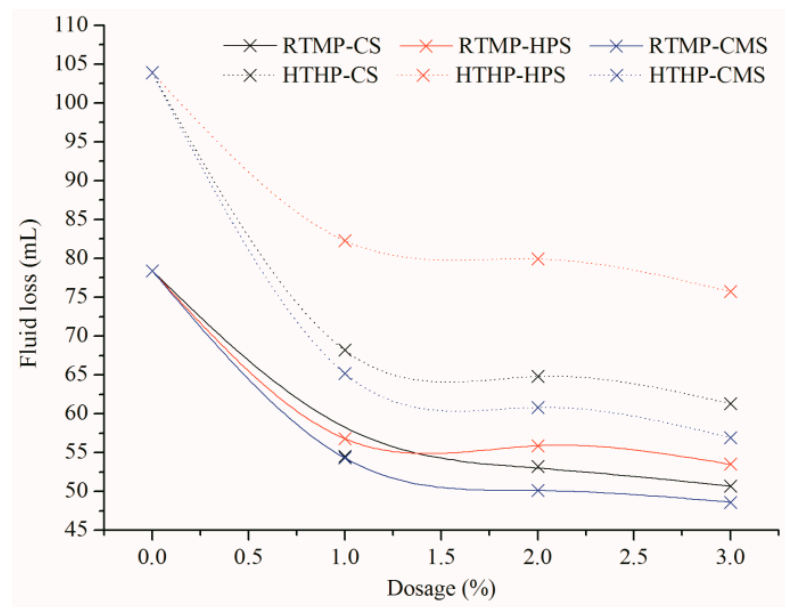

Figure 2. The static fluid loss of control and AAC with different dosage of CS, HPS and CMS.

Reference [30] has reported that poor fluid loss control of the cement slurry will lead to incomplete cement hydration and thus insufficient sealing of the borehole. A smaller fluid loss has a less negative effect on cementing quality and permeability of rock, and improves the stability of cement slurry [31]. CMS has a greater improvement in the fluid loss of AAC, when compared to CS and HPS, indicating that AAC with CMS will have an enhancement in cement quality and the stability.

\subsection{Setting Times}

Figure 3 shows the setting time of control and AAC with different dosages of starches at $85^{\circ} \mathrm{C}$. All the three starches prolong the setting time of the cement slurry. The prolonging influences increase as the increasing starch dosages. The sequence of the effects of starches is CMS > HPS > CS. The prolonging effect of HPS is close to CS, but that of CMS is slightly stronger. As reported in literature [32], the increment of alkali activator content leads to a slight increasing in cement setting time. The $\mathrm{pH}$ of the $1 \%, 2 \%$ and $3 \%(\mathrm{w} / \mathrm{v})$ CMS aqueous suspensions are $9.26,9.77$ and 10.12 , respectively. The values of $\mathrm{pH}$ of CMS suspensions are higher than 7.0, indicating they are alkaline. The anomalous alkaline $\mathrm{pH}$ values are attributable to the alkali existed in process of preparing the CMS. The residual alkali in CMS increases the alkalinity of the cement slurry, and thus further extends the setting time. 


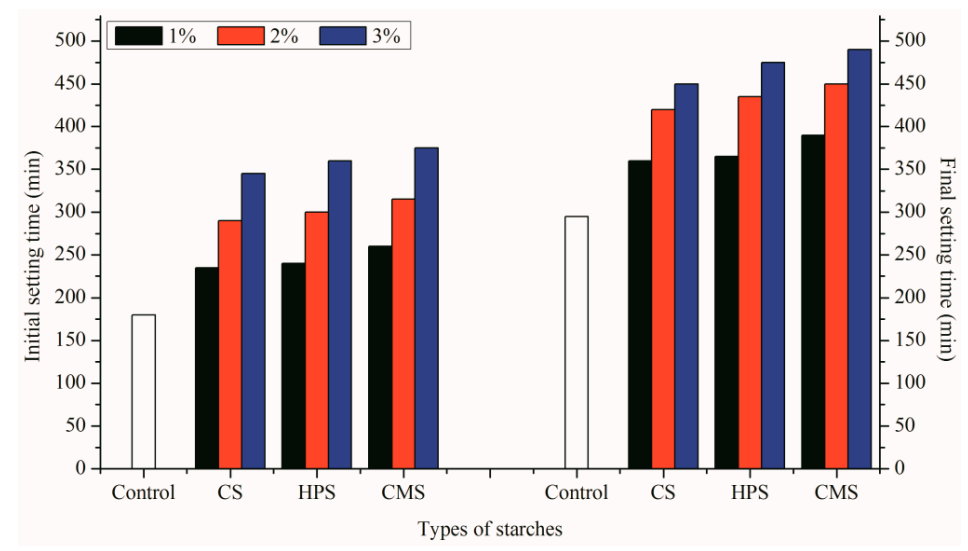

Figure 3. The setting time of control and AAC with different dosages of starches at $85^{\circ} \mathrm{C}$.

The results are in agreement with the viewpoint reported in [33] that polyhydroxy compounds have prolonging effects on cement setting. As hydration heat regulating materials, starches reduce the hydration heat by releasing the sugar chains on the cement particles [18]. This process also elongates the induction period of cement hydration, directly leads to an extension of the cement setting time.

References $[15,16]$ suggest that starches prolong the setting time due to their hydroxyls, which could complex $\mathrm{Ca}^{2+}$, and thus delay the hydration progress. Although the starches prolong the cement setting process, the delayed hydration progress can allow the cement to pump over a considerable distance of several kilometers [30].

\subsection{Compressive Strength}

As shown in Figure 4a, the compressive strength of $85{ }^{\circ} \mathrm{C}$-cured control is $17.56 \mathrm{MPa}$. The compressive strength decreases as the addition of CS and HPS. However, the addition of CMS has an increasing effect on the $85^{\circ} \mathrm{C}$-cured compressive strength. The compressive strengths of AAC with 3\% CS decreased by $13.72 \%$, when compared to control; the compressive strengths of AAC with $3 \%$ HPS decreased by $18.54 \%$. Combined with the results of setting time, we found that all three starches extend the cement setting time, and thus should decline the early age strength. However, the compressive strength of alkali-activated cement is also closely related to alkali activator content. As reported in [34], the compressive strength increases with the increasing alkali activator content. Although CMS extends the setting time to some extent, as the addition of CMS increases the alkalinity of cement slurry, $3 \% \mathrm{CMS}$ increases the $85^{\circ} \mathrm{C}$-cured compressive strength by $12.85 \%$.
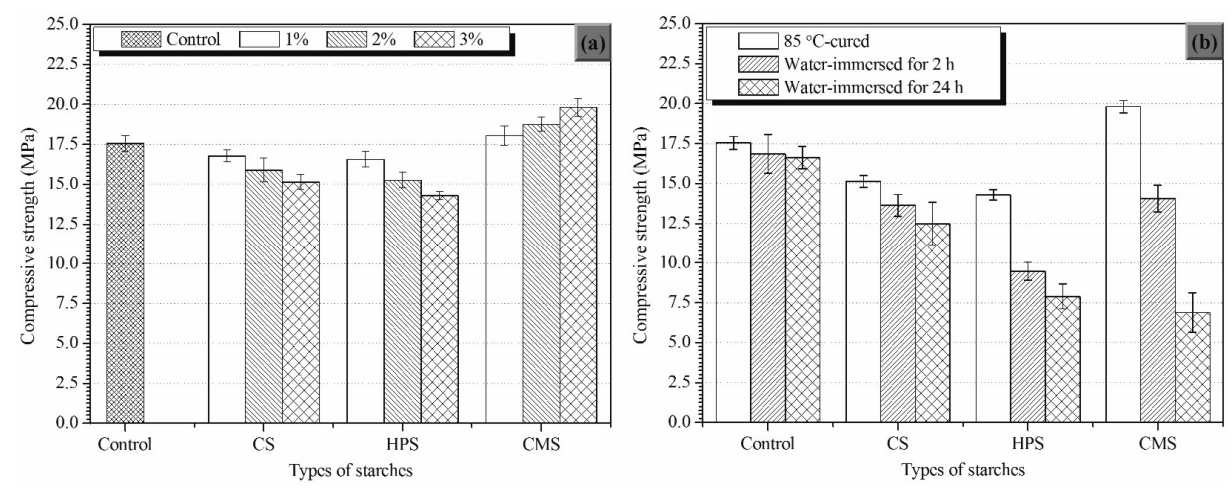

Figure 4. Compressive strengths of: (a) $85^{\circ} \mathrm{C}$-cured specimens of control and AAC with different dosages of starches; (b) $200{ }^{\circ} \mathrm{C}$-heated specimens after immersed in water for $2 \mathrm{~h}, 24 \mathrm{~h}$. 
As reported in [35], after curing circulation losses, the accepted compressive strength for resuming the drilling operations is $3.5 \mathrm{MPa}$. Therefore, although the $85^{\circ} \mathrm{C}$-cured compressive strength of the cement paste in this paper is about $18 \mathrm{MPa}$, it can still meet this requirement. In addition, as the ideal material should degrade after the drilling operation at $200{ }^{\circ} \mathrm{C}$ and contact with water, a lower water-immersed compressive strength of the $200^{\circ} \mathrm{C}$-heated cement are desirable.

Figure $4 \mathrm{~b}$ shows that the compressive strengths of all the cements decrease with the increase of immersion time. However, the reduction of control is much less than that of the cement with starches. The sequence of the decreasing effects of starches on water-immersed compressive strength is as follows: CMS > HPS > CS, when compared to their $85^{\circ} \mathrm{C}$-cured samples. The compressive strength of AAC with $3 \%$ CMS is decreased by $28.95 \%$ and $65.28 \%$, respectively, after $200{ }^{\circ} \mathrm{C}$-heated and immersed in water for $2 \mathrm{~h}$ and $24 \mathrm{~h}$.

After being heated, the cements were immersed in water for $2 \mathrm{~h}$ and $24 \mathrm{~h}$. The impregnation of water leads to some components of the cement dissolving. Besides that, the contact with pure water creates concentration gradients between the interstitial solution and the aggressive environment, as a result of which some ions in the pore solution diffuse outwards into the aggressive solution [36]. Leaching significantly reduces the compressive strength and stiffness of cement pastes [37]. Researchers have reported the decrease of mechanical properties of cementitious materials with the growth of leaching duration. Koo [38] has reported that the cumulative leach index shows an increasing trend as the water immersion time increases; the decreasing in compressive strength of the cement with an immersion time of 90 days was $58 \%$ of the compressive strength of the cement without immersion. Yang [36] tried to predict the calcium leaching behavior of cement pastes in aggressive environments, and reported that at the early period of leaching, a small increase in leaching durations corresponds to a large increase in strength loss.

\section{5. $X R D$}

Figure 5 shows XRD patterns of $85^{\circ} \mathrm{C}$-cured (a) and $200{ }^{\circ} \mathrm{C}$-heated (b) specimens of control and AAC with $3 \%$ starches. As shown in Figure $5 a, b$, the additions of the three starches do not change the peak position in patterns, when compared to control after $85^{\circ} \mathrm{C}$-cured or $20{ }^{\circ} \mathrm{C}$-heated, indicating that starches have no effect on the variety of AAC's hydration products. More significantly, however, there is an amorphous hump (between $2 \theta$ angles of $20^{\circ}$ and $38^{\circ}$ ) in each of the XRD patterns. The binder gels as the main reaction product in these hydrated $\mathrm{Na}_{2} \mathrm{O}-\mathrm{CaO}-\mathrm{Al}_{2} \mathrm{O}_{3}-\mathrm{SiO}_{2}$ system, promote the development of high mechanical strength and durability. The nature of the main type of gel formed depends on various factors, such as activator type and concentration, and the relative amounts of fly ash and slag [39].
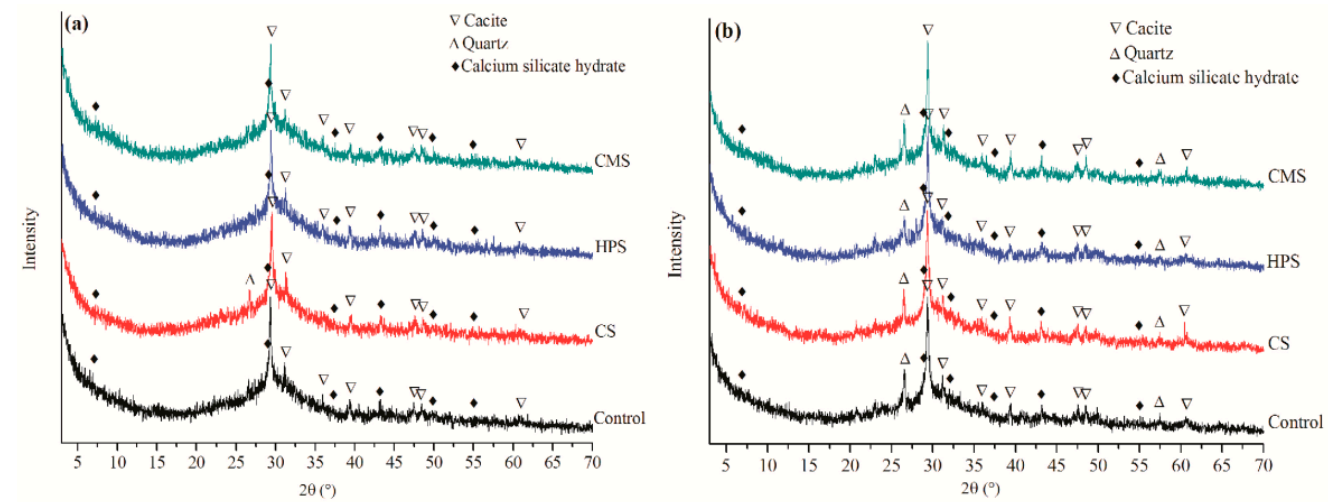

Figure 5. XRD patterns of $85^{\circ} \mathrm{C}$-cured (a) and $200{ }^{\circ} \mathrm{C}$-heated (b) specimens of control and AAC with $3 \%$ starches. 
References [40,41] reported that C-S-H $\left(\mathrm{C}-\mathrm{CaO}, \mathrm{S}-\mathrm{SiO}_{2}, \mathrm{H}-\mathrm{H}_{2} \mathrm{O}\right)$ gel dominates the reaction products, coexisting with aluminosilicate gels, and the diffuse peak at $20-25^{\circ}$ in $2 \theta$ indicates the formation of aluminosilicate gel. The literatures also reported that the amount of added slag primarily affected the amount of reaction product and its silicate structure: as the amount of added slag increased, the amount of C-S-H gel increased and the amount of aluminosilicate gel decreased.

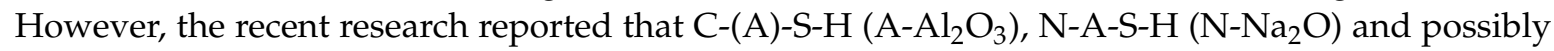
$\mathrm{N}-(\mathrm{C})-\mathrm{A}-\mathrm{S}-\mathrm{H}$ can be presented in the fly ash/slag blended systems [7]. Reference [42] reported that sodium metasilicate-activated fly ash/slag blends contain two distinct types of binder gel, one of which resembles the C-A-S-H gel formed through alkali silicate activation of slag, and the other is the N-A-S-H gel. The significant degree of Al substitution in C-S-H generates Al-substituted C-S-H type (C-A-S-H) gel. The interaction of the fly ash with the Na supplied by the activator can lead to the formation of N-A-S-H gel. References [39,43] reported the possibility of the formation of one hybrid C-N-A-S-H gel or the coexistence of N-A-S-H and C-A-S-H phases in the systems. In this paper, all patterns have an amorphous hump between $2 \theta$ angles $20^{\circ}$ and $25^{\circ}$, indicating the existence of aluminosilicate gel. The formula of the paste is $80 \mathrm{wt} . \%$ slag and $20 \mathrm{wt} . \%$ fly ash, with slag as the main ingredient. Besides that, the activator used in this paper is sodium metasilicate, which can supply $\mathrm{Na}$ ions to interact with the $20 \mathrm{wt} . \%$ fly ash and lead to the formation of N-A-S-H gel. Therefore, we believe that in this paper the C-A-S-H gel dominates the reaction products, with less N-A-S-H gel, and possibly some C-N-A-S-H gel. The variety of hydration products was not changed with the addition of starches.

Each of the XRD patterns in Figure 5 presents obvious peaks of calcite. The main part of calcite was formed during the preparation of samples, as the crushed hydrated cement contacted with $\mathrm{CO}_{2}$ in air. As reported in literature [44], $\mathrm{CO}_{2}$ could also react with calcium silicate hydrate to generate calcite and $\mathrm{SiO}_{2}$, at elevated temperatures $\left(200^{\circ} \mathrm{C}\right)$, as follows:

$$
\begin{gathered}
\mathrm{CO}_{2}+\mathrm{H}_{2} \mathrm{O} \rightarrow \mathrm{H}_{2} \mathrm{CO}_{3} \rightarrow \mathrm{H}^{+}+\mathrm{HCO}_{3}^{-}, \\
\mathrm{Ca}(\mathrm{OH})_{2}+\mathrm{H}^{+}+\mathrm{HCO}_{3}^{-} \rightarrow \mathrm{CaCO}_{3}+2 \mathrm{H}_{2} \mathrm{O}, \\
\mathrm{C}-\mathrm{S}-\mathrm{H}+\mathrm{H}^{+}+\mathrm{HCO}_{3}^{-} \rightarrow \mathrm{CaCO}_{3}+\mathrm{SiO}_{2}+\mathrm{H}_{2} \mathrm{O},
\end{gathered}
$$

The appearance of the $\mathrm{SiO}_{2}$ peaks in Figure $5 \mathrm{~b}$ verifies this viewpoint. In addition, the thermal degradation of starches generated $\mathrm{CO}_{2}$ and $\mathrm{H}_{2} \mathrm{O}$, which also reacted with the cement hydration products to form calcite, at $200{ }^{\circ} \mathrm{C}$. Meanwhile, [45] reported that starches have an affinity to complex calcium, under alkaline conditions. The process of sugar refining utilizes the flocculation of $\mathrm{CaCO}_{3}$ crystals derived from the reaction between $\mathrm{Ca}(\mathrm{OH})_{2}$ and $\mathrm{CO}_{2}$. A chemistry phenomenon has been observed in this process that if starch exists, more $\mathrm{Ca}(\mathrm{OH})_{2}$ is needed. Excessive calcite could decrease the compressive strength of cement by increasing the cement porosity and creating imperfect microstructures [44].

\subsection{Thermo Gravimetric Analysis (TGA) and DSC}

As the ideal material should plug the fractured formation at $85^{\circ} \mathrm{C}$, but degrade after the drilling operation at $200{ }^{\circ} \mathrm{C}$ and contact with water, the thermal property of the starches is an important index to evaluate the potential of starches as self-degradable additives. Figure 6 shows the TGA curves for the different (a) non-treated starches, and (b) filtrate-treated starches.

As shown in Figure 6a, the TGA curves of non-treated CS and non-treated HPS are similar. The TGA curve of non-treated CS presents three weight loss stages: the first stage is between room temperature and $251{ }^{\circ} \mathrm{C}$ with the weight loss of $14.90 \%$; the second stage is between $251{ }^{\circ} \mathrm{C}$ and $326^{\circ} \mathrm{C}$ with the weight loss of $66.28 \%$; the third stage is between $326^{\circ} \mathrm{C}$ and $450{ }^{\circ} \mathrm{C}$ with the weight loss of $13.64 \%$. The TGA curve of non-treated CMS also presents three weight loss stages: the first stage is between room temperature and $167^{\circ} \mathrm{C}$, with the weight loss of $10.16 \%$; the second stage is between $217{ }^{\circ} \mathrm{C}$ and $300{ }^{\circ} \mathrm{C}$, with the weight loss of $42.09 \%$; the third stage is between $300{ }^{\circ} \mathrm{C}$ and 
$450{ }^{\circ} \mathrm{C}$, with the weight loss of $12.08 \%$. All the main weight loss stages of these three starches are the second stage.

The second weight loss stages of the three starches, between about $200{ }^{\circ} \mathrm{C}$ and $350{ }^{\circ} \mathrm{C}$, are assigned to the thermal degradation of the starches. $\mathrm{Li}[46]$ has reported that, after carboxymethylation, the decomposition temperature of the native starch decreased from $316^{\circ} \mathrm{C}$ to $252^{\circ} \mathrm{C}$. Zhang [47] has also reported that the second decrease stage in weight of CMS, from $200^{\circ} \mathrm{C}$ to $350{ }^{\circ} \mathrm{C}$, corresponded to its thermal decomposition. The weight loss of non-treated CMS in the second stage is $42.09 \%$, which is smaller than the weight loss of non-treated of CS and HPS. This phenomenon is in agreement with [48].
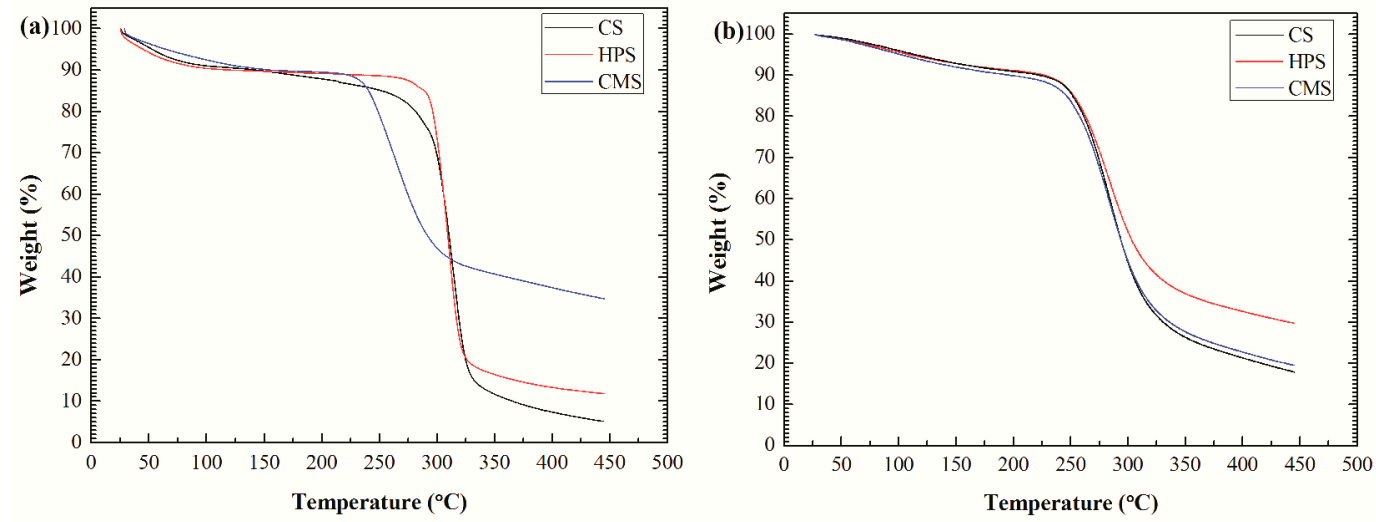

Figure 6. TGA curves for starches; (a) non-treated starches, (b) filtrate-treated starches.

As shown in Figure $6 \mathrm{~b}$, after the filtrate treatment process, all of the TGA curves of the three starches are similar. The main weight loss stage of CS is between $225^{\circ} \mathrm{C}$ and $330^{\circ} \mathrm{C}$ with the weight loss of $59.65 \%$; the main weight loss stage of HPS is between $225^{\circ} \mathrm{C}$ and $325^{\circ} \mathrm{C}$ with the weight loss of $48.67 \%$; and the main weight loss stage of CMS is between $215^{\circ} \mathrm{C}$ and $330^{\circ} \mathrm{C}$ with the weight loss of $57.80 \%$. The thermal degradation temperature of filtrate-treated CMS is $215^{\circ} \mathrm{C}$, slightly lower than that of CS and HPS.

Table 3 shows the weight ( $\mathrm{g}$ ) of non-treated, water-immersed and filtrate-treated starches before and after heating at $200{ }^{\circ} \mathrm{C}$ for $5 \mathrm{~h}$, and the corresponding weight loss (\%). The weight losses of the filtrate-treated CS, HPS and CMS are $28.57 \%, 30.56 \%$ and $35.14 \%$, respectively. The weight loss of CMS is larger, when compared to HPS and CS, resulting from its lower thermal degradation temperature. The lower thermal degradation temperature led to a higher degree of thermal degradation. As the thermal degradation of starches generates $\mathrm{CO}_{2}$ and $\mathrm{H}_{2} \mathrm{O}$, the larger weight loss indicates the generation of a larger amount of the products. As mentioned before, $\mathrm{CO}_{2}$ could react with the cement hydration products at $200^{\circ} \mathrm{C}$ to form excess calcite, which leads to an increasing of the cement porosity. The larger weight loss of CMS indicates that more calcite could be generated in AAC, at $200{ }^{\circ} \mathrm{C}$.

Table 3. The weight (g) of non-treated, water-treated and filtrate-treated starches before and after heated at $200{ }^{\circ} \mathrm{C}$ for $5 \mathrm{~h}$, and the weight loss (\%).

\begin{tabular}{cccccccccc}
\hline \multirow{2}{*}{ Samples } & \multicolumn{3}{c}{ Non-Treated Starches } & \multicolumn{3}{c}{ Water-Treated Starches } & \multicolumn{2}{c}{ Filtrate-Treated Starches } \\
\cline { 2 - 9 } & Before & After & Loss (\%) & Before & After & Loss (\%) & Before & After & Loss (\%) \\
\hline CS & 1.01 & 0.91 & 9.90 & 1.02 & 0.96 & 5.88 & 1.12 & 0.80 & 28.57 \\
HPS & 1.01 & 0.92 & 8.91 & 1.01 & 0.96 & 4.95 & 1.08 & 0.75 & 30.56 \\
CMS & 1.00 & 0.83 & 17.00 & 1.01 & 0.82 & 18.81 & 1.11 & 0.72 & 35.14 \\
\hline
\end{tabular}

Figure 7 shows the images of non-treated (a), water-immersed (b) and filtrate-treated (c) starches, before and after heating at $200{ }^{\circ} \mathrm{C}$ for 5 h: (1) CS, (2) HPS, (3) CMS. As shown in Figure 7c, the volume of filtrate-treated starches expanded after heated at $200{ }^{\circ} \mathrm{C}$ for $5 \mathrm{~h}$. Among all the samples, the volume 
expansion of the filtrate-treated CMS is the largest, followed by filtrate-treated HPS and CS. On the contrary, all of the volume of non-treated starches, and the water-immersed CS and HPS do not show the expansion phenomenon, as shown in Figure 7a,b. The volume of water-immersed CMS displays a slight expansion.

The $\mathrm{pH}$ value of the filtrate is 13.16 , indicating that the filtrate is alkaline. The alkali activator, sodium metasilicate dissolved in water of cement, led to the alkalinity. References [46,49-52] have reported that alkali promotes the pasting of starch by combining - $\mathrm{OH}$ to consume hydrogen bonds in starch, destroys the starch granule through charge-induced chain repulsion in the granule, and thus swells starch granules. The swelling starch granules take up more volume than solubilized starch solutions or more compact, rigid granules. The $\mathrm{pH}$ of $3 \%(\mathrm{w} / \mathrm{v})$ CS suspension and $3 \%(\mathrm{w} / \mathrm{v}) \mathrm{HPS}$ suspension are 7.34 and 7.26. However, the $\mathrm{pH}$ of $3 \%(\mathrm{w} / \mathrm{v}) \mathrm{CMS}$ suspension is 10.12, which is alkaline. On the one hand, the alkaline CMS increased the alkalinity of filtrate-treated samples. On the other hand, the stronger alkaline conditions also promoted the swelling of starch granules. This is the reason for the phenomenon that the volume expansion of filtrate-treated CMS is larger than that of filtrate-treated CS and HPS.

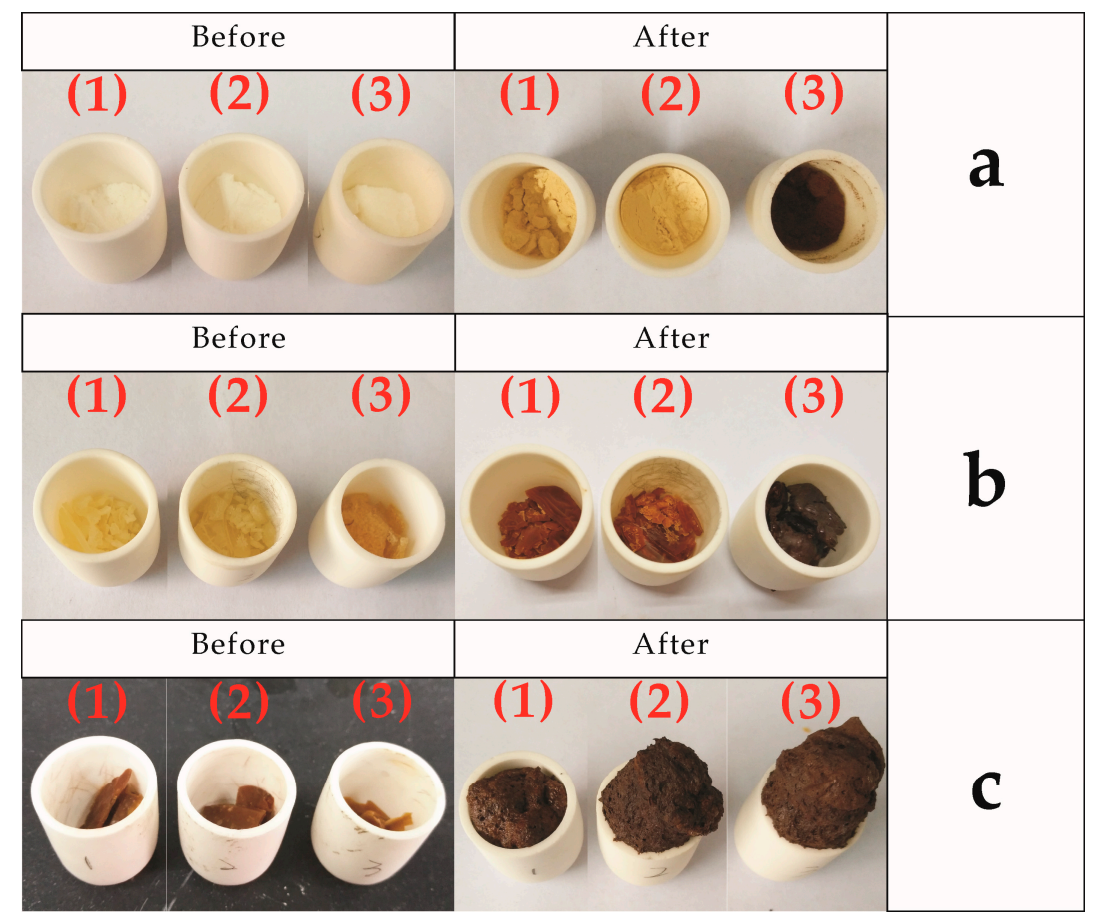

Figure 7. The images of non-treated: (a) water-treated; (b) and filtrate-treated; (c) starchesafter heated at $200{ }^{\circ} \mathrm{C}$ for $5 \mathrm{~h}$ : (1) CS; (2) HPS; (3) CMS.

The volume expansion of starch granules in cement also attributes to the increased cement porosity. The larger volume expansion and the larger weight loss of filtrate-treated CMS after heating at $20{ }^{\circ} \mathrm{C}$ indicate that the addition of CMS has a larger ability to increase the cement porosity, and thus has greater potential as a self-degradable additive in AAC.

DSC tests of the starches with distilled water (CS, HPS and CMS) and the starches with the cement filtrate (CS-1, HPS-1 and CMS-1) were carried out to investigate the effects of filtrate on starches. As shown in Figure 8, the peak gelatinization temperature of CS and HPS are $67.5^{\circ} \mathrm{C}$ and $57.2^{\circ} \mathrm{C}$. Both the thermographs of CMS and CMS-1 have no peak. As shown in CS-1 and HPS-1, the peaks in thermographs of CS and HPS disappear with the presence of the cement filtrate, indicating that CS-1 and HPS-1 have gelatinized before the test. The results verify the effects of alkaline filtrate on starches that it promotes the gelatinization of the starches. 


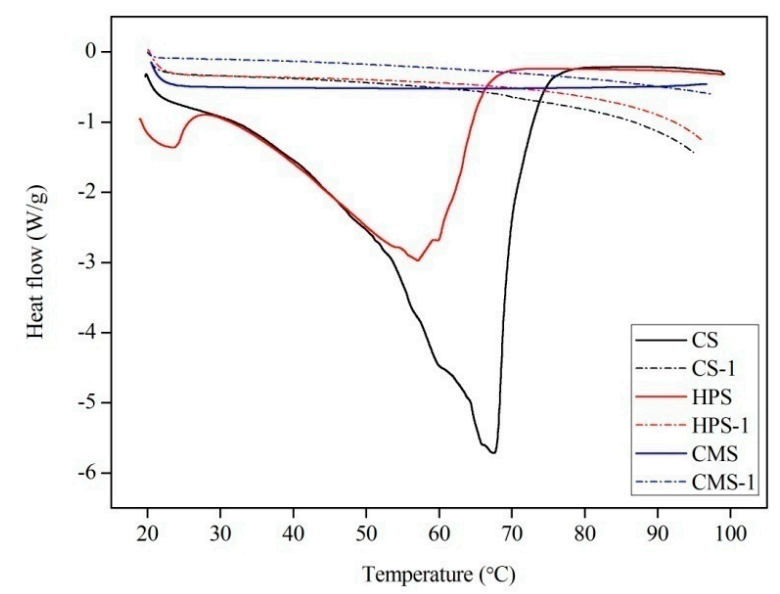

Figure 8. DSC thermographs of the starches with distilled water (CS, HPS and CMS) and the starches with the cement filtrate (CS-1, HPS-1 and CMS-1).

\subsection{FTIR}

In order to further investigate the effects of cement filtrate on starches, FTIR spectra were recorded for the non-treated starches $(\mathrm{N})$, the filtrate-treated starches before $(\mathrm{F})$ and after $(\mathrm{A})$ being heated at $20{ }^{\circ} \mathrm{C}$ for $5 \mathrm{~h}$. The FTIR spectra of the starches are shown in Figure 9: (a) CS; (b) HPS; (c) CMS. There are several similar bands at 2927, 1590, 1413, 1336, 1083, 782, and $462 \mathrm{~cm}^{-1}$ of FTIR spectra for CS-A, HPS-A and CMS-A, indicating that these filtrate-treated starches generated the same products after $200{ }^{\circ} \mathrm{C}$ heating.
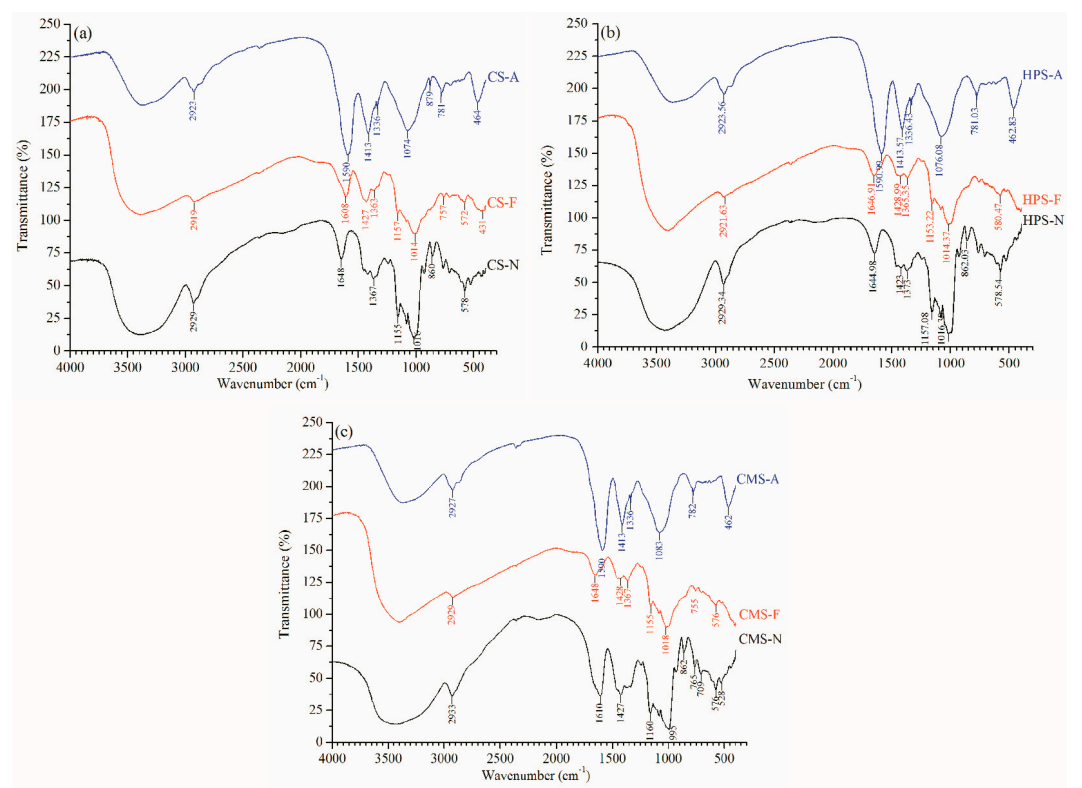

Figure 9. The FTIR spectra of non-treated starches $(\mathrm{N})$, the filtrate-treated starches before $(\mathrm{F})$ and after (A) heated at $200{ }^{\circ} \mathrm{C}$ for 5 h: (a) CS; (b) HPS; (c) CMS.

As shown in the FTIR spectra of the CS-A, HPS-A and CMS-A, the band between 3000 and $3900 \mathrm{~cm}^{-1}$, attributed to hydrogen-bonded hydroxyls in the starch molecules, becomes smaller after filtrate-treatment; and then the band becomes smaller and narrower after heating, indicating the hydrogen-bonded hydroxyls were consumed during the filtrate-treatment period and the $200{ }^{\circ} \mathrm{C}$-heating period. The results verify that alkali in the filtrate promotes the pasting of starch by combining with -OH groups to destroy the hydrogen bonds in starch. 
The band at $2931 \mathrm{~cm}^{-1}$ attributed to $\mathrm{CH}_{2}$ symmetrical stretching vibrations, remains after filtrate-treatment, but becomes smaller after heating, indicating that it was consumed during the heating period. The bands around $861 \mathrm{~cm}^{-1}$ and $764 \mathrm{~cm}^{-1}$ in the three non-treated starches are attributed to skeletal stretching vibrations of starches [48,53]. The bands between 1200 and $700 \mathrm{~cm}^{-1}$ are mainly attributed to polysaccharides and their isomers [54]: the bands around $1157 \mathrm{~cm}^{-1}$ are assigned to stretching vibration of C-O and C-C. These bands around $1157 \mathrm{~cm}^{-1}$ are almost constant in FTIR spectra of the CS-F, HPS-F and CMS-F after the filtrate treatment, but disappear after the $200{ }^{\circ} \mathrm{C}$-heating in FTIR spectra of the CS-A, HPS-A and CMS-A. These changes indicate that the filtrate treatment period does not consume the $\mathrm{CH}_{2}, \mathrm{C}-\mathrm{C}$ and $\mathrm{C}-\mathrm{O}$ groups, but the heating treatment consumes them.

For the $200{ }^{\circ} \mathrm{C}$-heated starches, there are three bands at 1590, 1413 and $1336 \mathrm{~cm}^{-1}$. These three bands are attributed to - $\mathrm{COO}^{-}$, indicating the existence of carboxylate groups in these heated-starches [54]. The bands around $3300 \mathrm{~cm}^{-1}$ are assigned to residual -OH. The sharp peak at $1000 \mathrm{~cm}^{-1}$ is attributed to silicate [55]. The silicate results from sodium metasilicate in the filtrate. During the $200{ }^{\circ} \mathrm{C}$-heating period, the groups of $\mathrm{CH}_{2}, \mathrm{O}-\mathrm{H}, \mathrm{C}-\mathrm{C}$, and $\mathrm{C}-\mathrm{O}$ reduced with a corresponding relative growth of the silicate and carboxylate bands in the samples. The thermal degradation of starches generates $\mathrm{CO}_{2}$ and $\mathrm{H}_{2} \mathrm{O}$, consuming the organic groups in starches during the heating period.

In general, the filtrate-treatment period does not consume the $\mathrm{CH}_{2}, \mathrm{C}-\mathrm{C}$ and $\mathrm{C}-\mathrm{O}$ groups, but the alkali in the filtrate promotes pasting of starches by combining - $\mathrm{OH}$ to destroy hydrogen bonds in the starches; the thermal degradation of the starches consumes the organic $\mathrm{CH}_{2}, \mathrm{C}-\mathrm{C}$ and $\mathrm{C}-\mathrm{O}$ groups, and further consumes - $\mathrm{OH}$; the products of the filtrate-treated starches after the $200{ }^{\circ} \mathrm{C}$-heated contain silicate and carboxylate functions.

\subsection{Self-Degradation}

The microstructures of $85{ }^{\circ} \mathrm{C}$-cured cement after $200{ }^{\circ} \mathrm{C}$-heated and immersed in water were studied to evaluate the effect of starches on the self-degradability of the material. Figure 10 shows the images observed by a polarizing microscope of $200^{\circ} \mathrm{C}$-heated specimens: (a) control, (b) AAC with 3\% CS, (c) AAC with 3\% HPS, (d) AAC with 3\% CMS. As shown in Figure 10a, the image of control is compact without any visible pores. However, in Figure $10 b-d$, there are some visible pores. The number of the pores increases in accordance with the sequence of CS, HPS and CMS. Especially, with the addition of $3 \%$ CMS, the compact cement structures changed to honeycomb-like structures after the heat treatment.

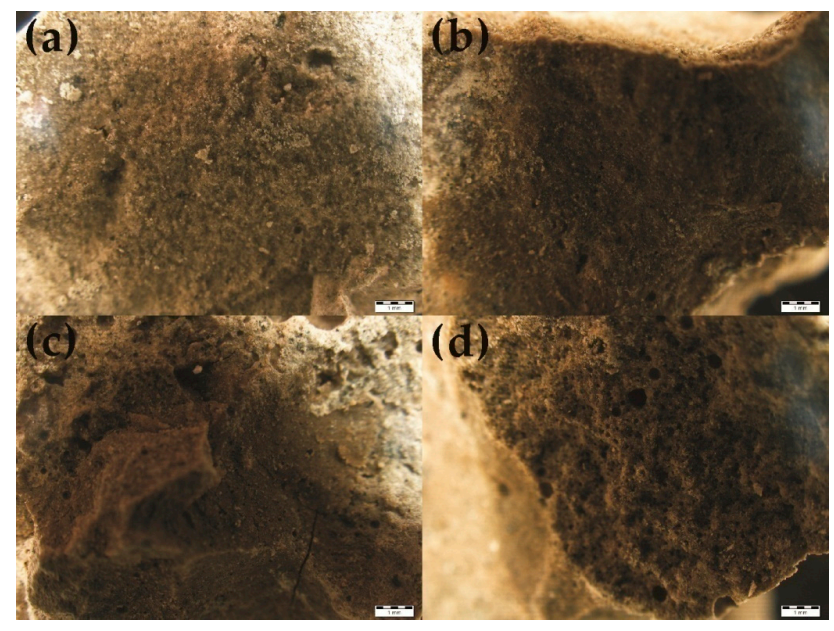

Figure 10. Images observed by a polarizing microscope of $200{ }^{\circ} \mathrm{C}$-heated specimens: (a) control; (b) AAC with 3\% CS; (c) AAC with 3\% HPS; (d) AAC with 3\% CMS. 
Section 3.6 shows the weight loss and volume expansion of the filtrate-treated starches after being heated. The starches in the alkali activated cement began to degrade and expand during the heating period. As mentioned before, $\mathrm{CO}_{2}$ and $\mathrm{H}_{2} \mathrm{O}$, generated by the thermal degradation of the starches, could react with the cement hydration products to form $\mathrm{CaCO}_{3}$. Meanwhile, starches have an affinity to complex calcium to generate $\mathrm{CaCO}_{3}$. Both the volume expansion and the excess $\mathrm{CaCO}_{3}$ could increase the cement porosity, and thus lead to these honeycomb structures in the cement.

Figure 11 shows SEM images of $200^{\circ} \mathrm{C}$-heated specimens immersed in water for $24 \mathrm{~h}$ : (a) control, (b) AAC with 3\% CS, (c) AAC with 3\% HPS, (d) AAC with 3\% CMS. It could be observed that the sequence of the density of the specimens is $(a)>(b)>(c)>(d)$. Besides that, there are some cracks in (c) and (d), especially in (d). The density of the structures directly affects the strength of the samples. Loose internal structures lead to a strength decline [56].

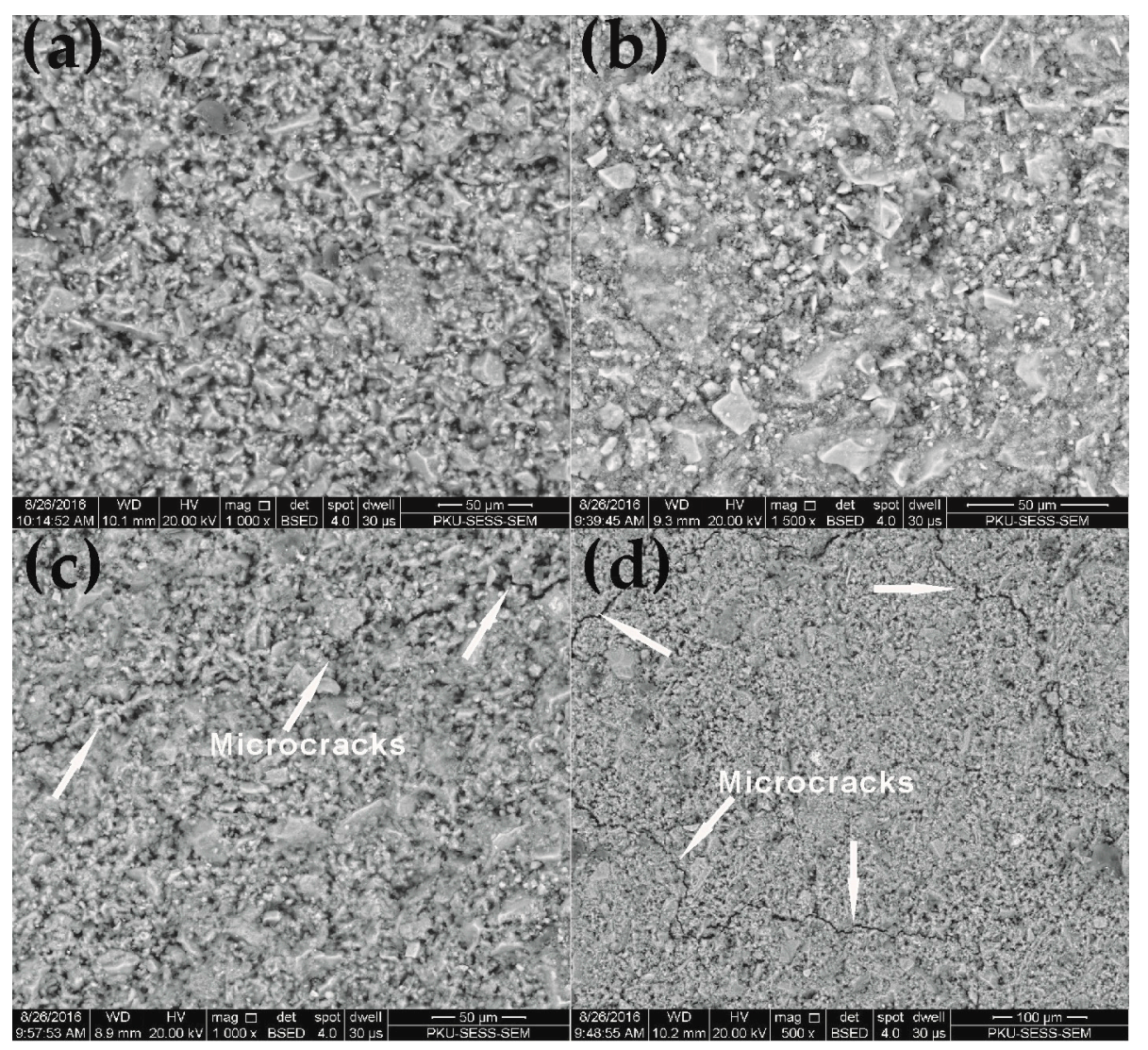

Figure 11. SEM images of $200{ }^{\circ} \mathrm{C}$-heated specimens immersed in water for $24 \mathrm{~h}$ : (a) control, AAC with (b) $3 \%$ C; (c) $3 \%$ HPS; (d) $3 \%$ CMS.

To further study the density of the specimens in Figure 11, the BJH pore size distribution $(<130 \mathrm{~nm})$ test and the apparent porosity tests were carried out. Figure 12 shows the BJH pore size distribution of $200{ }^{\circ} \mathrm{C}$-heated specimens of control, AAC with 3\% CS (CS-3), AAC with 3\% HPS (HPS-3) and AAC with 3\% CMS (CMS-3). All of the peaks of pore size distribution are around $3.8 \mathrm{~nm}$. The height sequence of the peaks that could be obviously observed, is CMS-3 > HPS-3 > CS-3 > control. Total pore volume for pores smaller than $130 \mathrm{~nm}$ of the control is $0.165 \mathrm{~cm}^{3} / \mathrm{g}$. The values of AAC with $3 \%$ CS, AAC with $3 \%$ HPS and AAC with $3 \%$ CMS are $0.239 \mathrm{~cm}^{3} / \mathrm{g}, 0.251 \mathrm{~cm}^{3} / \mathrm{g}$ and $0.263 \mathrm{~cm}^{3} / \mathrm{g}$. The addition of starches thus increases the total pore volume for pores smaller than $130 \mathrm{~nm}$ of the specimens, when compared to control. 


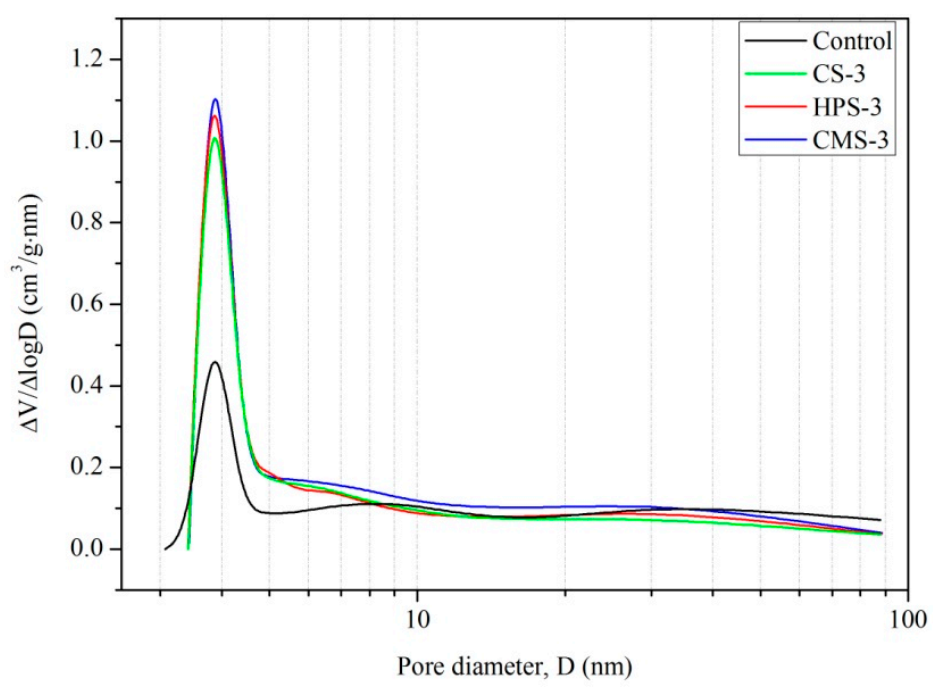

Figure 12. Pore size distribution $(<130 \mathrm{~nm})$ of $200{ }^{\circ} \mathrm{C}$-heated specimens immersed in water for $24 \mathrm{~h}$.

Table 4 shows the apparent porosity of $200{ }^{\circ} \mathrm{C}$-heated specimens of control, AAC with $3 \%$ CS (CS-3), AAC with 3\% HPS (HPS-3) and AAC with 3\% CMS (CMS-3) after immersion in water for $24 \mathrm{~h}$. The apparent porosity of control is $24.10 \%$. With the addition of $3 \% \mathrm{CMS}$, the apparent porosity of control is increased from $24.10 \%$ to $40.74 \%$. The results of the $\mathrm{BJH}$ pore size distribution and the apparent porosity verify the judgement about Figure 11 that the sequence of the density of specimens is $(\mathrm{a})>(\mathrm{b})>(\mathrm{c})>(\mathrm{d})$.

Table 4. The value of $m_{d}(\mathrm{~g}), m_{s}(\mathrm{~g}), m_{i}(\mathrm{~g})$ and apparent porosity $(\%)$ of $200{ }^{\circ} \mathrm{C}$-heated specimens immersed in water for $24 \mathrm{~h}$.

\begin{tabular}{ccccc}
\hline Samples & $\boldsymbol{m}_{\boldsymbol{d}}$ & $\boldsymbol{m}_{\boldsymbol{s}}$ & $\boldsymbol{m}_{\boldsymbol{i}}$ & Apparent Porosity \\
\hline Control & 123.8 & 136.5 & 83.8 & 24.10 \\
CS-3 & 121.2 & 139.2 & 81.5 & 31.19 \\
HPS-3 & 120.6 & 141.7 & 82.3 & 35.52 \\
CMS-3 & 122.5 & 148.9 & 84.1 & 40.74 \\
\hline
\end{tabular}

After being heated, the cement was immersed in water. The impregnation of water led to some cement components being dissolved. Besides that, contact with pure water creates concentration gradients between the interstitial solution and the aggressive environment of these cementitious materials, as a result of which some ions in the pore solution diffuse outwards into the aggressive solution. The leaching process has been investigated previously [57-59].

As reported, the porosity is an important parameter characterizing the microstructure evolution of cement-based materials caused by calcium leaching in a water environment, and it can reflect the leaching behavior of cement-based materials [58]. The initial porosity of cement paste has a large impact on its calcium leaching process. Tang has [59] reported that the reduction of water-binder ratio improved the compactness and initial porosity of slag cement pastes, and decreased the diffusion rate of calcium ions in pore solution, leading to an enhanced calcium leaching resistance. On the contrary, large initial porosity leads to a decreased leaching resistance. Due to the thermal degradation and volume expanding, the addition of the starches increases the number of pores in $200^{\circ} \mathrm{C}$-heated cement, namely, increases the initial porosity. The density of the structures directly affects the strength of the samples, due to the loose internal structure leading to a strength decline. The larger initial porosity not only indicates looser structures in the cement, but also leads to a faster leaching process, and thus promotes the degradation. 
Figure 7 predicts that CMS will show a greater volume expansion, when compared to CS and HPS. The structures of AAC with 3\% CMS are also looser than CS and HPS, as shown in Figures 10 and 11. We suggest the degradation process of the material contains CMS involves the following: (1) the thermal degradation and volume expansion of CMS made the structures of $200{ }^{\circ} \mathrm{C}$-heated cement become looser; (2) the looser structures of $200^{\circ} \mathrm{C}$-heated cement with a larger initial porosity made the leaching process become faster; (3) as the leaching time grew, the decrease of compressive strength and appearance of cracks in the cement occurred.

In addition, the ideal material should also provide a higher compressive strength to seal at $85^{\circ} \mathrm{C}$ during drilling. CMS increases the $85{ }^{\circ} \mathrm{C}$-cured compressive strength of the material. Therefore, it has the greatest potential as a self-degradable additive for geothermal cement. However, as the compressive strength of $200{ }^{\circ} \mathrm{C}$-heated AAC with $3 \%$ CMS immersed in water for $24 \mathrm{~h}$ is $6.88 \mathrm{MPa}$, the degradation is not thorough enough. A study of further promoting the self-degradation of the material by increasing the dosage of CMS or simultaneously adding other self-degradable additives will be conducted, in the future.

\section{Conclusions}

All the tested starches have the effects of increasing the apparent viscosity, prolonging the setting time, and reducing the fluid loss of AAC. Among the three starches, CMS has the greatest decreasing effect on static fluid loss.

After $200{ }^{\circ} \mathrm{C}$ heating, all three of the filtrate-treated starches presented volume expansion, and generated the same products containing silicate and carboxylate groups. CMS presented the greatest volume expansion, as the alkaline CMS increased the alkalinity of filtrate-treated samples, and the stronger alkaline conditions promoted the swelling of starch granules.

The thermal degradation and volume expansion of starch made the structures of $200{ }^{\circ} \mathrm{C}$-heated cement become loose; the loose structures of $20{ }^{\circ} \mathrm{C}$-heated cement with a large initial porosity made the subsequent leaching process become faster; as the leaching time grew, the decrease of compressive strength and appearance of cracks in the cement were presented.

In this paper, CMS has the greatest potential as a self-degradable additive for alkali-activated cement. The AAC with $3 \%$ CMS presented the loosest structures after the process of $200{ }^{\circ} \mathrm{C}$-heating and being immersed in water, and achieved a $12.85 \%$ increase in $85{ }^{\circ} \mathrm{C}$-cured compressive strength.

As the degradation was not thorough enough in this paper, a study of how to further promote the self-degradation of the material by increasing the dosage of CMS or simultaneously adding other self-degradable additives will be conducted in the future.

Acknowledgments: This work was supported by the National Natural Science Foundation of China (Grant No. 41572361) of "Design and Preparation of Green Environmental Friendly of Self-degradable Foamed Temporary Cementitious Sealing Materials for Geothermal Reservoir", and the Fundamental Research Funds for the Central Universities (Grant No. 2652017068). The authors also would like to thank the Key Laboratory of Deep Geodrilling Technology, Ministry of Land and Resources, the Demonstration Center for Experimental Geological Resources Exploration Education, and the National International Joint Research Center of Deep Geodrilling Equipment.

Author Contributions: The contributions of each author are as follows: Huijing Tan performed the main experiments, analyzed the experimental results and wrote the manuscript. Xiuhua Zheng conceived and designed the experiments, provided guidance and reviewed the manuscript. Limenglu Ma and Haixiao Huang performed partial experiments, analyzed partial experimental results and wrote manuscript. Bairu Xia supervised the research throughout the whole process, reviewed the paper and gave advices about this manuscript. All authors have read and approved the final manuscript.

Conflicts of Interest: The authors declare no conflict of interest.

\section{References}

1. Navigant Consulting Inc. Comparative Cost of California Central Station Electricity Generation Technologies. California Energy Commission; CEC-200-2007-011; 2007. Available online: http://www.energy.ca.gov/ 2007publications/CEC-200-2007-011/CEC-200-2007-011-SF-APB.PDF (accessed on 18 July 2017). 
2. Finger, J.; Blankenship, D. (Eds.) Lost circulation. In 2010 Handbook of Best Practices for Geothermal Drilling, 1st ed.; Sandia National Laboratories: Albuquerque, NM, USA, 2010.

3. Stafford, C.E. Measuring the Success of EGS Projects: An Historical to Present Day Perspective. In Proceedings of the Australian Geothermal Energy Conference, Adelaide, Australia, 16-19 November 2010; 2010; pp. 210-213. Available online: https:/ / www.geothermal-energy.org/pdf/IGAstandard/AGEC/2010/ Stafford_2010.pdf (accessed on 18 July 2017).

4. Irassar, E.F.; Bonavetti, V.L.; Gonza'lez, M. Microstructural study of sulfate attack on ordinary and limestone Portland cements at ambient temperature. Cem. Concr. Res. 2003, 33, 31-41. [CrossRef]

5. Sugama, T.; Brothers, L.E.; Van de Putte, T.R. Acid-resistant cements for geothermal wells: Sodium metasilicate activated slag/fly ash blends. Adv. Cem. Res. 2005, 17, 65-75. [CrossRef]

6. Aliques-Granero, J.; Tognonvi, T.M.; Tagnit-Hamou, A. Durability Test Methods and their Application to Aams: Case of Sulfuric-Acid Resistance. Mater. Struct. 2017, 50, 1-14. [CrossRef]

7. Lee, N.K.; Koh, K.T.; An, G.H.; Ryu, G.S. Influence of binder composition on the gel structure in alkali activated fly ash/slag pastes exposed to elevated temperatures. Ceram. Int. 2017, 43, 2471-2480. [CrossRef]

8. Abdalqader, A.F.; Jin, F.; Al-Tabbaa, A. Development of greener alkali-activated cement: Utilisation of sodium carbonate for activating slag and fly ash mixtures. J. Clean. Prod. 2016, 113, 66-75. [CrossRef]

9. Nelson, E.; Barlet-Gouedard, V. Thermal cements. In Well Cementing, 2nd ed.; Nelson, E., Guillot, D., Eds.; Schlumberger: Sugar Land, TX, USA, 2006.

10. Sugama, T.; Pyatina, T. Effect of sodium carboxymethyl celluloses on water-catalyzed self-degradation of 200 degrees C-heated alkali-activated cement. Cem. Concr. Compos. 2015, 55, 281-289. [CrossRef]

11. Sugama, T.; Butcher, T.; Brothers, L.; Bour, D. Temporary cementitious sealing materials. In Proceedings of the Geothermal Resources Council Transactions 2011 Annual Meeting, San Diego, CA, USA, 23-26 October 2011.

12. Yan, J. Technologies of Drilling Fluid, Revised ed.; China University of Petroleum Press: Beijing, China, 2011; pp. 139-140.

13. Liu, X. Thermal Decomposition of Starch and Starch-Based Materials. Doctor's Thesis, South China University of Technology, Guangzhou, China, 2011.

14. Mendes, A.C.; Boesel, L.F.; Reis, R.L. Degradation studies of hydrophilic, partially degradable and bioactive cements (HDBCs) incorporating chemically modified starch. J. Mater. Sci.-Mater. Med. 2012, 3, 667-676. [CrossRef] [PubMed]

15. Shi, C. The Preparation and Performance of Water-Reducing Retarder Based on Starch. Master's Thesis, Chongqing University, Chongqing, China, 2009.

16. Wang, T. The Study on the Cement-Based Material Water-Reducing Prepared by Modified Starch. Master's Thesis, Southwest University of Science and Technology, Mianyang, China, 2010.

17. Lv, Z.; Yu, C.; She, S.; Wu, J.; Wang, T.; Ran, Q. Preparation and action mechanism of starch-based cement hydration heat regulating materials. J. Build. Mater. 2016, 4, 625-630.

18. Feng, Y.C.; Gray, K.E. Review of fundamental studies on lost circulation and wellbore strengthening. J. Pet. Sci. Eng. 2017, 152, 511-522. [CrossRef]

19. Romero, S.; Monroy, R.R.; Johnson, C.R.; Cardenas, F.; Torres Abraham, G.A. Preventing lost circulation by use of lightweight slurries with reticular systems: Depleted reservoirs in southern Mexico. Soc. Pet. Eng. 2006, 21, 185-192. [CrossRef]

20. Mehrabian, A.; Jamison, D.E.; Teodorescu, S.G. Geomechanics of lost-circulation events and wellbore-strengthening operations. Soc. Pet. Eng. 2015, 20, 1305-1316. [CrossRef]

21. Kohl, T.; Megel, T. Predictive modeling of reservoir response to hydraulic stimulations at the European EGS site Soultz-sous-Forets. Int. J. Rock Mech. Min. Sci. 2007, 44, 1118-1131. [CrossRef]

22. Portier, S.; Vuataz, F.D.; Nami, P.; Sanjuan, B.; Gerard, A. Chemical stimulation techniques for geothermal wells: Experiments on the three-well EGS system at Soultz-sous-Forets, France. Geothermics 2009, 38, 349-359. [CrossRef]

23. Rafiq, S.I.; Singh, S.; Saxena, D.C. Effect of alkali-treatment on physicochemical, pasting, thermal, morphological and structural properties of horse chestnut (Aesculus Indica) starch. J. Food Meas. Charact. 2016, 10, 676-684. [CrossRef]

24. ASTM International. Standard Test Methods for Apparent Porosity, Water Absorption, Apparent Specific Gravity, and Bulk Density of Burned Refractory Brick and Shapes by Boiling Water; ASTM International: West Conshohocken, PA, USA, 2000. 
25. Zhang, Z.L.; Sui, T.B.; Chen, F.Y.; Wen, S.J.; Shi, H.X.; Wang, J.; Fan, L. Determined the rheological properties of HBC cement paste slurry using rotational viscometer. Liaoning Build. Mater. 2005, 1, 18-20.

26. Vipulanandan, C.; Mohammed, A. Smart cement rheological and piezoresistive behavior for oil well applications. J. Pet. Sci. Eng. 2015, 135, 50-58. [CrossRef]

27. Wang, W.; Wang, K.; Xiao, J.; Liu, Y.; Zhao, Y.; Liu, A. Performance of high amylose starch-composited gelatin films influenced by gelatinization and concentration. Int. J. Biol. Macromol. 2017, 94, 258-265. [CrossRef] [PubMed]

28. Su, H.; Ji, S.; Liu, Z. Study on the correlation between the index of cement slurry filtrate loss and water loss. Inner Mongolia Pet. Ind. 2010, 23, 135-137.

29. Song, B.; Zhang, M.; Mu, Z.; He, Y.; Zhang, W. Damage analysis and protection technology of slurry filtrate to oil and gas reservoir. Oil Drill. Prod. Technol. 2005, 1, 27-28.

30. Hurnaus, T.; Plank, J. Synthesis, Characterization and performance of a novel phosphate modified fluid loss additive useful in oil well cementing. J. Nat. Gas Sci. Eng. 2016, 36, 165-174. [CrossRef]

31. Li, M.; Xie, D.; Guo, Z.; Lu, Y.; Guo, X. A novel terpolymer as fluid loss additive for oil well cement. Int. J. Polym. Sci. 2017, 2017, 3940394. [CrossRef]

32. Shi, C.J.; Krivenko, P.V.; Roy, D. Alkali-Activated Cements and Concretes, 1st ed.; Chemical Industry Press: Beijing, China, 2008; pp. 70-74.

33. Shen, X.; Yao, Y. Research Progress of Cementitious Materials, 1st ed.; Higher Education Press: Beijing, China, 2012; pp. 446-447.

34. Dai, K. Study on the Cementitious System of the Slag and Fly Ash Mixture. Master's Thesis, Daqing Petroleum Institute, Daqing, China, 2009.

35. Thiercelin, M. Mechanical properties of well cements. In Well Cementing, 2nd ed.; Nelson, E., Guillot, D., Eds.; Schlumberger: Sugar Land, TX, USA, 2006.

36. Yang, H.; Jiang, L.; Zhang, Y.; Pu, Q.; Xu, Y. Predicting the Calcium leaching behavior of cement pastes in aggressive environments. Constr. Build. Mater. 2012, 29, 88-96. [CrossRef]

37. Kuryatnyk, T.; Chabannet, M.; Ambroise, J.; Pera, J. Leaching behaviour of mixtures containing plaster of Paris and calcium sulphoaluminate clinker. Cem. Concr. Res. 2010, 40, 1149-1156. [CrossRef]

38. Koo, D.S.; Sung, H.H.; Kim, S.S.; Kim, G.N.; Choi, J.W. Characteristics of cement solidification of metal hydroxide waste. Nucl. Eng. Technol. 2017, 49, 165-171. [CrossRef]

39. Ismail, I.; Bernal, S.A.; Provis, J.L.; Nicolas, R.S.; Hamdan, S.; van Deventer, J.S.J. Modification of phase evolution in alkali-activated blast furnace slag by the incorporation of fly ash. Cem. Concr. Compos. 2014, 45, 125-135. [CrossRef]

40. Lee, N.K.; Lee, H.K. Reactivity and reaction products of alkali-activated, fly ash/slag paste. Constr. Build. Mater. 2015, 81, 303-312. [CrossRef]

41. Kumar, S.; Kumar, R.; Mehrotra, S.P. Influence of granulated blast furnace slag on the reaction, structure and properties of fly ash based geopolymer. J. Mater. Sci. 2010, 45, 607-615. [CrossRef]

42. Bernal, S.A.; Provis, J.L.; Walkley, B.; Nicolas, R.S.; Gehman, J.D.; Brice, D.G.; Kilcullen, A.R.; Duxson, P.; van Deventer, J.S.J. Gel nanostructure in alkali-activated binders based on slag and fly ash, and effects of accelerated carbonation. Cem. Concr. Res. 2013, 53, 127-144. [CrossRef]

43. Marjanovic, N.; Komljenovic, M.; Bascarevic, Z.; Nikolic, V.; Petrovic, R. Physical-mechanical and microstructural properties of alkali-activated fly ash-blast furnace slag blends. Ceram. Int. 2015, 41, 1421-1435. [CrossRef]

44. Zhang, J.; Wang, Y.; Xu, M.; Zhao, Q. Effect of carbon dioxide corrosion on compressive strength of oilwell cement. J. Chin. Ceram. Soc. 2009, 37, 642-647.

45. Tang, P.; Liu, Y.; Liu, J. Effect of lime on gelatinization of heat-treatment corn flour. Food Sci. Technol. 2016, 41, 186-190.

46. Li, X.; Gao, W.; Huang, L.; Wang, Y.; Huang, L.; Liu, C. Preparation and physicochemical properties of carboxymethyl fritillaria ussuriensis maxim. Starches. Carbohydr. Polym. 2010, 80, 768-773. [CrossRef]

47. Zhang, B.; Tao, H.; Wei, B.; Jin, Z.; Xu, X.; Tian, Y. Characterization of different substituted carboxymethyl starch microgels and their interactions with lysozyme. PLoS ONE 2014, 9, e114634. [CrossRef] [PubMed]

48. Lawal, O.S.; Lechner, M.D.; Kulicke, W.M. The synthesis conditions, characterizations and thermal degradation studies of an etherified starch from an unconventional source. Polym. Degrad. Stab. 2008, 93, 1520-1528. [CrossRef] 
49. Somasundaran, P. Encyclopedia of Surface and Colloidal Science, 2nd ed.; CRC Press: Florida, FL, USA, 2006.

50. Sangseethonga, K.; Ketsilp, S.; Sriroth, K. The role of reaction parameters on the preparation and properties of carboxymethyl cassava starch. Starch-Starke 2005, 57, 84-93. [CrossRef]

51. Cao, Y.; Liu, Z.; Yu, H. Influences of alkali treatment time on properties of starch-based wood adhesives. China Adhes. 2014, 23, 576-580.

52. Yang, G.; Fan, T. Study on the modified corn starch adhesive. China Adhes. 2003, 12, 34-37.

53. Ren, J.; Liu, G.; Ou, Q.; Zhao, S.; Xu, J.; Ma, D. Starch discrimination with Fourier Transform Infrared Spectroscopy (FTIR) and Two-dimensional Correlation Infrared Spectroscopy (2D-IR). Chin. Agric. Sci. Bull. 2015, 31, 58-64.

54. Weng, S. Fuliye Bianhuan Hongwai Guangpu Fenxi, 2nd ed.; Chemical Industry Press: Beijing, China, 2010; pp. 291-362.

55. $\mathrm{Xu}, \mathrm{J}$. Infrared spectroscopy analysis is of modified sodium metasilicate. Foundry 2008, 57, 835-838.

56. Zhang, Z.H.; Li, L.F.; Ma, X.; Wang, H. Compositional, microstructural and mechanical properties of ambient condition cured alkali-activated cement. Constr. Build. Mater. 2016, 113, 237-245. [CrossRef]

57. Allahverdi, A.; Mehrpour, K.; Kani, E.N. Investigating the possibility of utilizing pumice-type natural pozzonal in production of geopolymer cement. Ceram. Silik. 2008, 52, 16-23.

58. Tang, Y.; Zuo, X.; Yin, G.; He, S.; Ayinde, O. Influence of slag on leaching behavior of cement mortar lined in ductile iron pipe under a flowing solution. Mater. Des. 2017, 114, 612-622. [CrossRef]

59. Tang, Y.; Zuo, X.; He, S.; Ayinde, O.; Yin, G. Influence of slag content and water-binder ratio on leaching behavior of cement pastes. Constr. Build. Mater. 2016, 129, 61-69. [CrossRef]

(C) 2017 by the authors. Licensee MDPI, Basel, Switzerland. This article is an open access article distributed under the terms and conditions of the Creative Commons Attribution (CC BY) license (http:/ / creativecommons.org/licenses/by/4.0/). 